\title{
Holocord spinal epidural abscess in a pregnant patient presenting as premature labour: a rare presentation of an unusual diagnosis
}

\author{
Kirsteen R. Burton, MSc, MBA, MD*t+; Xi Wang, MD ${ }^{\S}$; \\ Deljit Dhanoa, BASc, MD, MBA, CCFP(EM), DABR"
}

\section{ABSTRACT}

Spinal epidural abscess (SEA) is a rare clinical entity. It is less common when the entire epidural space is involved, known as a holocord or panspinal SEA, and it is even less common in a pregnant patient. We report a case of methicillin-resistant Staphylococcus aureus holocord SEA in a 30-year-old female at approximately 22 weeks' gestational age who presented with lumbar pain and pelvic pressure and the urge to bear down. Magnetic resonance imaging of the spine demonstrated extensive SEA and meningitis from the foramen magnum to the lumbar spine that was treated both medically and surgically. The incidence of, clinical presentation of, and risk factors for developing SEA are discussed. If untreated, expanding SEAs produce sensory symptoms and signs, motor dysfunction, and, eventually, paralysis and death. The medical and surgical management of SEA is also discussed. SEA can have an insidious and atypical presentation despite extensive involvement of the epidural space. Therefore, the diagnosis of SEA should always be considered in patients who present to the emergency department with back pain.

\section{RÉSUMÉ}

L'abcès épidural rachidien (AER) est une entité clinique rare; celui-ci l'est encore plus lorsque l'abcès envahit tout l'espace épidural—on le qualifie alors de panrachidien—et il devient rarissime chez une femme enceinte. Ainsi sera exposé, dans le présent article, un cas d'abcès épidural panrachidien à Staphylococcus aureus résistant à la méthicilline, chez une femme de 30 ans, enceinte d'environ 22 semaines, qui a consulté pour des douleurs lombaires, une pression pelvienne et l'envie impérieuse de pousser. L'imagerie par résonance magnétique de la colonne vertébrale a révélé la présence d'un important $A E R$ et d'une méningite s'étendant du trou occipital à la colonne lombaire, qui a nécessité un traitement médical et chirurgical. II sera question de la fréquence, du tableau clinique, et des facteurs de risque de I'AER. Non traitée, l'affection produit des signes et symptômes sensoriels ainsi que des troubles moteurs, qui finissent par évoluer vers la paralysie et la mort. Le traitement médical et chirurgical de I'AER fera également I'objet de discussion. Ce dernier peut se manifester par un tableau insidieux et atypique malgré l'étendue de l'atteinte de l'espace épidural. Aussi faudrait-il toujours envisager la possibilité d'un AER chez les patients qui consultent au service des urgences pour des dorsalgies.

Keywords: back pain, emergency, epidural abscess, magnetic resonance imaging, methicillin-resistant Staphylococcus aureus, osteomyelitis, pregnancy

Spinal epidural abscess (SEA) is an uncommon disorder that is less common when it involves the entire spinal canal in a pregnant patient. This case describes a methicillin-resistant Staphylococcus aureus holocord SEA in a 30-year-old pregnant woman. We review the epidemiology of the condition and describe the medical imaging findings, treatment options, and prognosis.

\section{CASE REPORT}

A 30-year-old pregnant female, who was 21 weeks and 5 days of gestational age, presented to the emergency department (ED) complaining of lower back pain. The patient believed the pain was related to her kidneys because she had experienced similar pain previously,

From the *Institute of Health, Policy, Management and Evaluation, †Medical Imaging, and ¥Biostatistics, University of Toronto, Toronto, ON; $\S$ Department of Diagnostic Radiology, McMaster University, Hamilton, ON; and ॥ Medical Imaging, University of British Columbia, Fraser Health Authority, Vancouver, BC.

Correspondence to: Dr. Deljit Dhanoa, Department of Radiology, Faculty of Medicine, University of British Columbia, 3350-950 W 10th Avenue, Vancouver BC V5Z 4E3; dhanoad@yahoo.com.

This article has been peer reviewed. 
which was diagnosed as a genitourinary infection. The emergency physician performed a urine dipstick analysis, which was negative, and the fetal heart rate was normal using fetal Doppler ultrasonography. The patient was afebrile, and no antipyretics were administered to the patient prior to ED presentation. The patient did not complain of a fever, and there was no history of intravenous (IV) drug use on the initial visit. A neurologic examination was not performed on the initial visit, and Obstetrics/Gynecology was not consulted. The patient was discharged with the diagnosis of muscular back pain and referred to her family physician for follow-up.

Four days later, the patient presented to a different ED with acute pelvic pressure and the urge to bear down. The patient did not complain of a fever at the second presentation. The pertinent negatives on the history by the emergency physician were absence of nausea, vomiting, vaginal bleeding, or a history suggestive of ruptured membranes. The patient's past social history was significant for cocaine use 1 week prior to presentation, remote IV drug use, and a history of prostitution. The patient's previous medical history was significant for asthma and iron deficiency anemia; she was hepatitis $\mathrm{C}$ positive and human immunodeficiency virus (HIV) and hepatitis $B$ negative.

Vital signs were as follows: temperature $37.3^{\circ} \mathrm{C}$ (oral; $99.1^{\circ} \mathrm{F}$ ), blood pressure 116/72 $\mathrm{mm} \mathrm{Hg}$, respiratory rate 24 breaths/min, pulse 108 beats/min, and $100 \%$ oxygen saturation on room air. A physical examination, including a screening neurologic examination that included gross sensory and motor skills of all four extremities, was unremarkable. There were no signs of saddle anesthesia or urinary retention, and rectal tone was documented as normal. The patient was discharged home after normal obstetric ultrasonography was performed. The discharge plan was to obtain serology including a complete blood count (CBC) and, in the interim, send the patient home with acetaminophen for pain control and follow-up with her obstetrician.

Shortly postdischarge, the patient's white blood cell count returned at $48.2 \times 10^{9}$ cells $/ \mathrm{L}$. The patient was contacted and requested to return to the ED for reassessment via ambulance later the same day. Her vital signs at that time were as follows: temperature $37.5^{\circ} \mathrm{C}$ (oral; $99.5^{\circ} \mathrm{F}$ ); blood pressure 94/54 mm Hg; respiratory rate 18 breaths/min; pulse 110 beats/min; and $100 \%$ oxygen saturation on room air. At this third presentation, she reported back pain with movement and generalized weakness. On examination, she exhibited neck stiffness but normal sensory and motor function in all limbs. Assessment for saddle anesthesia, rectal tone, and urinary retention was not documented. A lumbar puncture was performed due to the clinical concern of meningitis, and frank pus was obtained.

Given the findings on lumbar puncture, empirical antibiotic therapy was initiated (cloxacillin and vancomycin), and gadolinium-enhanced magnetic resonance imaging (MRI) of the spine was performed (Figure 1 and Figure 2). The MRI demonstrated marked enhancement of the spinal meninges from the foramen magnum to the sacrum. A rim-enhancing epidural collection measuring up to $1.8 \mathrm{~cm}$ in its widest diameter extended from the upper to the lower lumbar spine. The abnormal enhancement extended into the paraspinal muscles and into the right psoas muscle consistent with extraspinal extension of infection, resulting in pyomyositis and intramuscular abscesses (Figure 3).

The patient was transferred to a neurosurgical tertiary care centre the same day, which was 5 days after the initial presentation, at which time, the patient's neurologic status deteriorated significantly. She became lethargic and was unable to ambulate due to a combination of pain with movement and weakness. The only motion that she was able to perform actively was extension and flexion of the great toe on one side. Power in the lower legs was $1 / 5$, and the only deep tendon reflex that could be elicited was a left Achilles tendon reflex of $1+$. Subsequently, a partial T12 and L1/L2 laminectomy and epidural abscess evacuation 5 days after initial presentation were performed. In the

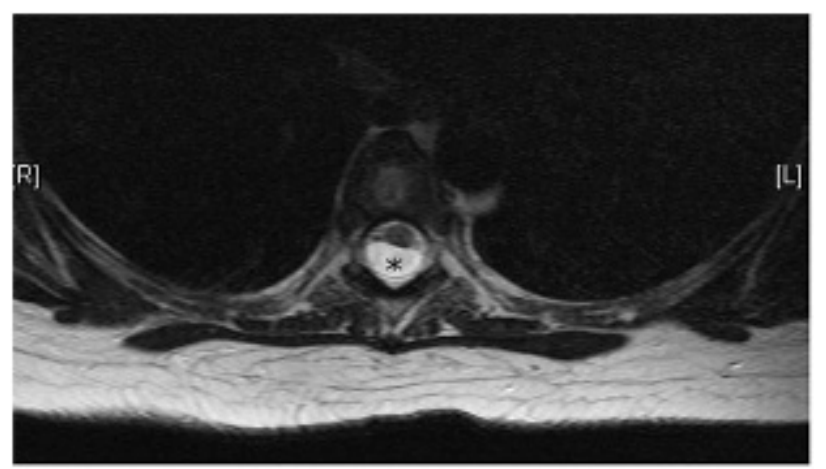

Figure 1. Axial $T_{2}$-weighted magnetic resonance imaging study of the midthoracic spine showing a $T_{2}$ hyperintense collection of pus in the dorsal epidural space $(*)$ causing mass effect on the thecal sac and displacing it ventrally. 


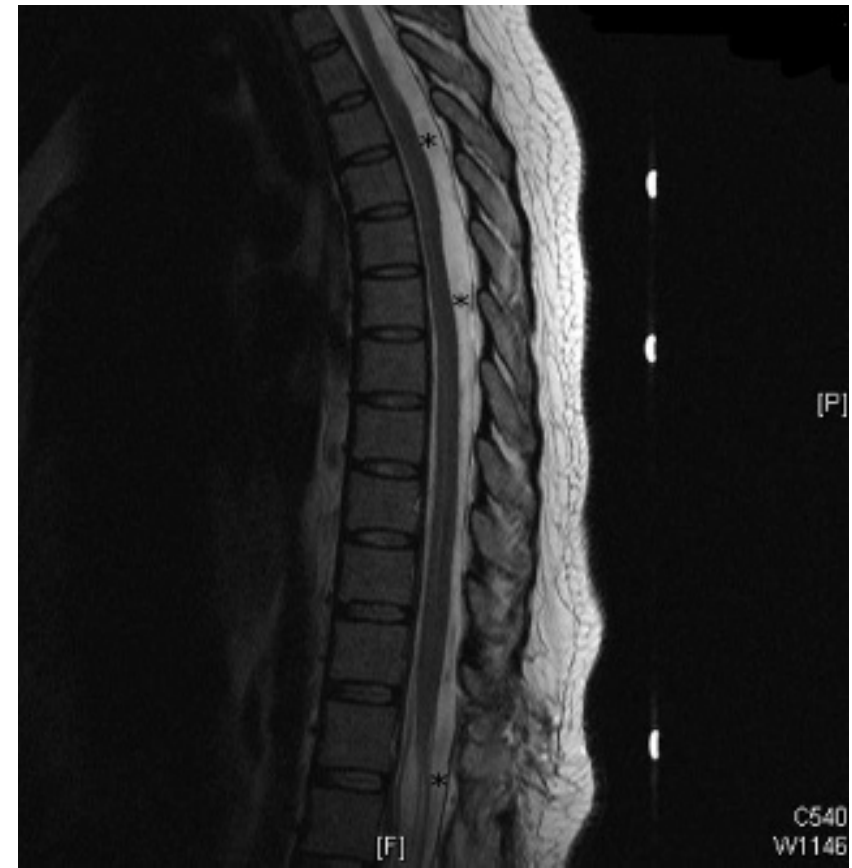

Figure 2. Sagittal $T_{2}$-weighted magnetic resonance imaging study of the thoracolumbar spine showing a $T_{2}$ hyperintense collection of pus involving the entire length of the thoracic and lumbar spine $\left({ }^{*}\right)$ that is applying mass effect to the thecal sac and spinal cord. operating room, immediately on removing the laminae, white pus extruded from the spinal canal.

The patient recovered slowly during the following months. Subsequent MRIs demonstrated abscess resolution and minimal residual enhancement of the meninges involving the lower thoracic, lumbar spinal cord, and cauda equina. One day following completion of the vancomycin therapy and at 32 weeks and 4 days of gestational age, the patient left against medical advice. At that time, she was ambulatory and continent of stool; however, she remained retentive of urine unless self-catheterization was performed.

The patient was readmitted at 37 weeks and 6 days of gestational age for a cesarean section. An infant was delivered with Apgar scores of 7 and 9 at 1 and 5 minutes, respectively; her post-cesarean section recovery was unremarkable. The patient was discharged, at her request, on postoperative day 2. At that point, her bowels were functioning well, although she required self-catheterization for urinary retention.

\section{DISCUSSION}

SEA is a rare clinical entity, and when it involves the entire cervicothoracolumbar spine (holocord), it is

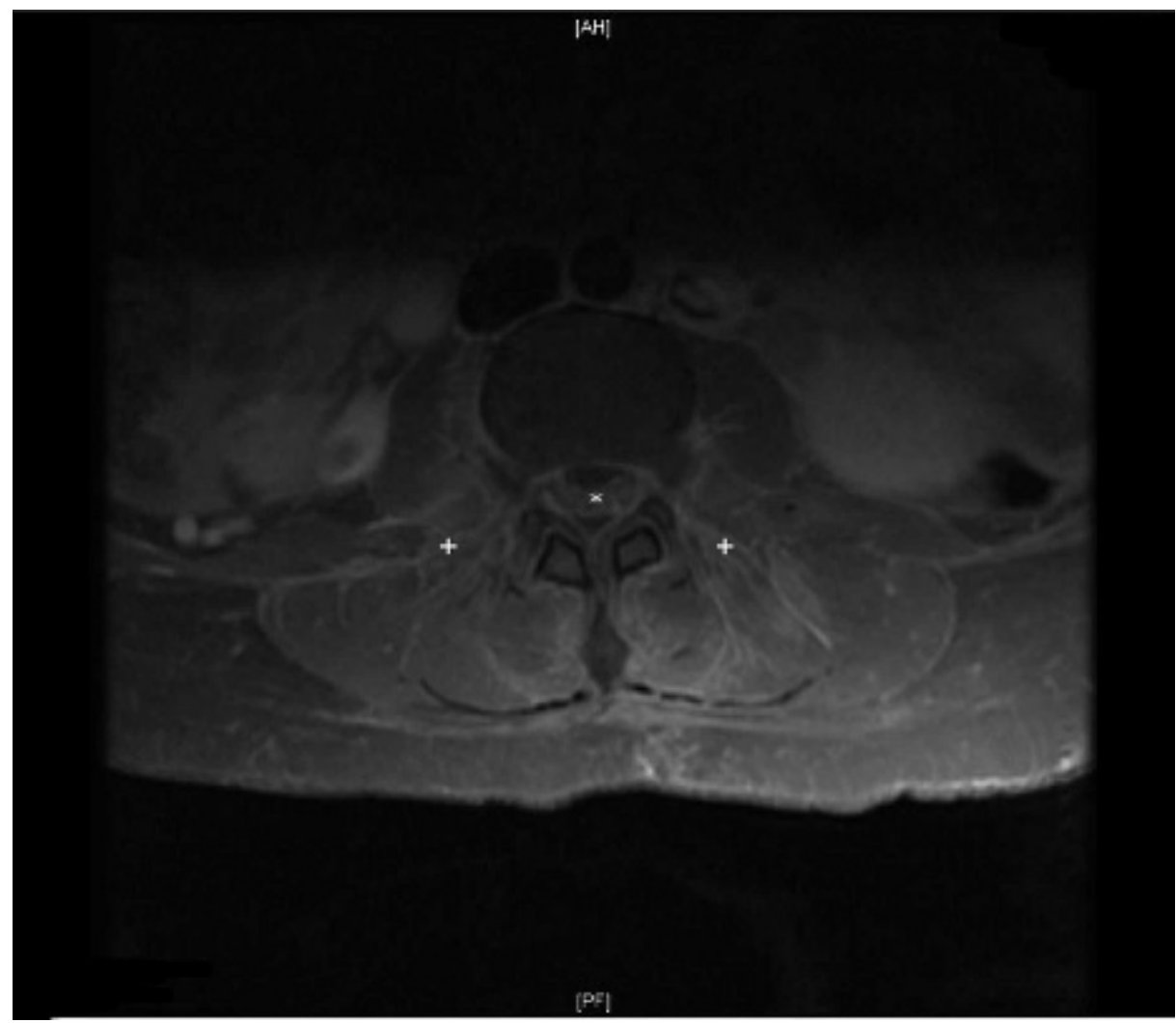

Figure 3. Contrast-enhanced magnetic resonance image of the lower thoracic spine showing rim enhancement of the dorsal epidural collection $(*)$ as well as enhancement of the paraspinal muscles $(+)$ and psoas muscles bilaterally consistent with an epidural abscess and pyomyositis of the involved muscle groups. 
even rarer; only 12 such cases are reported in the literature. ${ }^{1}$ There are no cases in the literature of a holocord SEA diagnosed in a pregnant patient. Fortunately, in our case, the fetus was not adversely affected; however, in this case, the pregnancy served as a major distracting variable for the treating emergency physicians. The pregnancy also increased the risk of morbidity and mortality because two lives were put at risk with this life-threatening diagnosis.

The incidence of SEA is approximately 0.2 to 1.2 cases per 10,000 hospital admissions, although higher rates have been cited. ${ }^{2-4}$ There is no accurate reported incidence of holocord SEA in the literature. ${ }^{5}$ The incidence is also felt to be on the rise, which is thought to be due to increasing IV drug use, chronic immunosuppression, and the increasing number of spinal surgeries being performed. ${ }^{6}$ Additional risk factors include diabetes mellitus, chronic renal failure, HIV infection, alcoholism, malignancy, morbid obesity, septicemia, and systemic immune deficiency. ${ }^{3}$ The most common mechanisms are hematogenous spread and direct extension, and the most common infectious agent is Staphylococcus aureus ${ }^{7}$; however, in up to half of all patients, a clear causative source cannot be identified. ${ }^{8}$ SEAs threaten the vascular supply and function of the spinal cord from mass effect and vascular compromise. If untreated, the expanding abscess produces sensory symptoms and signs, motor dysfunction, and, eventually, paralysis and death. Despite recent advances in diagnostic imaging and antibiotic therapies, SEA still portends significant morbidity and mortality. ${ }^{9-11}$

The spinal epidural space is not a uniform oneposteriorly, the epidural space contains fat and blood vessels, whereas anteriorly, the dura adheres to the vertebral bodies centrally. This is a potential space, and as such, SEAs tend to collect in the anatomic area of least resistance. They have a tendency for multilevel spread and also tend to occur most commonly in the thoracic region, presumably because this is anatomically the longest portion of the spinal canal. In up to half of all patients, a clear source is not delineated. ${ }^{8}$ Clinical symptoms arise due to compression of vascular supply and infarction rather than direct compression of the cord itself. The most common organisms identified include $S$. aureus, Pseudomonas spp, Escherichia coli, and Mycobacterium tuberculosis. Once SEA is suspected, gadolinium-enhanced MRI is the imaging modality of choice for initial confirmation and subsequent follow-up. ${ }^{1}$
When diagnosed, early intervention is essential for full functional recovery. The prognosis, in general, is related to the duration of spinal cord dysfunction and the degree of cord impairment at the time of diagnosis. ${ }^{12}$ There is frequently a delay in diagnosis, however, because the initial presentation is often vague. The classic triad of fever, spine pain, and neurologic abnormalities is present in only 10 to $15 \%$ of initial presentations. ${ }^{13}$ In one key article on this topic, the authors state that diagnostic delays occurred in $75 \%$ of the patients they reviewed. ${ }^{14}$

Due to the difficulty in detecting this entity clinically and the frequency of diagnosis delays, emergency physicians should consider the possibility of SEA in all patients who present with back pain and fever. Emergency physicians should identify the risk factors described above for SEA, which would act as a guide to determine the pretest likelihood, thereby determining the appropriateness of further investigation such as MRI with contrast. To assist emergency physicians, Davis and colleagues created a novel decision guideline to assist in the identification of patients with SEA. ${ }^{15}$ These guidelines follow an algorithm that takes progressive neurologic deficits and clinical presentation including fever, risk factors, and erythrocyte sedimentation rate/ C-reactive protein as baseline characteristics to aid the physician in determining the threshold for medical imaging. Regardless of the management strategy used, one of the learning objectives for this case is that SEA should be considered in all patients presenting to the ED with back pain.

The treatment of SEA depends on a number of factors, including the patient's clinical presentation and the findings on medical imaging. Although the cornerstone of treatment is antimicrobial therapy and surgical decompression, there is no consensus on when surgical management of SEA should be performed, if at all, once antimicrobial therapy has been initiated. The management of holocord SEA is also controversial given the exceedingly rare incidence. One article suggests that patients who are candidates for drug therapy are those who are not surgical candidates, those who only exhibit spinal ache or radicular pain, patients whose abscess does not involve an extensive length of the spinal canal, and those who have had complete paralysis for more than 72 hours. ${ }^{16}$ If, however, the patient is exhibiting deteriorating neurologic status, increasing pain, pyrexia, or leukocytosis, then immediate surgical decompression in 
addition to antibiotics is warranted. Multilevel SEA could be treated surgically by multilevel laminectomies, but this increases the complication rates, such as blood loss, cardiorespiratory issues, and future kyphosis and spinal instability. ${ }^{17}$ There has also been a description of laminectomies performed at the cranial and caudal ends of the epidural abscess. A sterile balloon is placed from one end and is inflated and then withdrawn from the opposite end to extract the pus in the spinal canal. ${ }^{18}$ This technique could be considered for the patient in our case report. Given the extent of our patient's SEA on imaging and her clinical deterioration, she was decompressed surgically undergoing multilevel laminectomies and interoperative irrigation.

This case highlights the importance of early diagnosis and intervention in holocord SEA and illustrates the discordance between a patient's initial presenting symptoms and the degree of pathology. These are important considerations given the low incidence of SEAs, the high associated morbidity, and the propensity for delayed diagnosis, most especially in patients with few risk factors. Prompt use of MRI should help decrease the time to diagnosis and possibly decrease the incidence of more severe morbidity and mortality.

\section{CONCLUSION}

This case illustrates that SEA can have an insidious and nonclassic presentation despite extensive involvement of the epidural space. Fortunately, the pregnancy was not adversely affected by the SEA; however, it serves as a confounding variable that challenges the emergency physician to make the correct diagnosis but also adds an extra element of comorbidity to the clinical situation. The diagnosis of SEA should be considered by the clinician in patients who present to the ED with back pain and symptoms and signs suggestive of of an infectious etiology. If clinically suspected, MRI evaluation with contrast enhancement is the standard imaging modality for assessment of the epidural space. Current management strategies include urgent referral to Neurosurgery and Infectious Disease for medical therapy and, in select cases, consideration for surgical treatment based on the patient's clinical presentation.

Competing interests: None declared.

\section{REFERENCES}

1. Wessling H, de las Heras P. Cervicothoracolumbar spinal epidural abscess with tetraparesis. Neurochirurgia 2003;14: 529-33.

2. Baker AS, Ojemann RG, Swartz MN, Richardson EP Jr. Spinal epidural abscess. N Engl 7 Med 1975;293:463-8, doi:10.1056/NEJM197509042931001.

3. Hllavin M, Kaminski H, Ross J. Spinal epidural abscess. A ten-year perspective. Neurosurgery 1990;27:177-84, doi:10. 1227/00006123-199008000-00001.

4. Pilkingon SA, Jackson SA, Gillett GR. Spinal epidural empyema. Br $\mathcal{F}$ Neurosurg 2003;17:196-200, doi:10.1080/ 0268869031000108990.

5. Darouiche RO. Spinal epidural abscess. N Engl 7 Med 2006; 355:2012-20, doi:10.1056/NEJMra055111.

6. Pradilla G, Pradilla Ardila G, Hsu W, Rigamonti D. Epidural abscesses of the CNS. Lancet Neurol 2009;8:292300, doi:10.1016/S1474-4422(09)70044-4.

7. Del Curling OJ, Gower D, McWhorter J. Changing concepts in spinal epidural abscess: a report of 29 cases. Neurosurgery 1990;27:185-92, doi:10.1227/00006123-199008000-00002.

8. Rea G, McGregor J, Miller C. Surgical treatment of the spontaneous spinal epidural abscess. Surg Neurol 1992;37: 274-9, doi:10.1016/0090-3019(92)90152-D.

9. Rigamonti D, Liem L, Sampath P. Spinal epidural abscess: contemporary trends in etiology, evaluation, and management. Spine 1999;52:189-97.

10. Deardre C, Nanda A. Spinal epidural abscess: a diagnostic challenge. Am Fam Physician 2002;65:1341-6.

11. Harrington P, Millner P, Veale D. Inappropriate medical management of spinal epidural abscess. Ann Rheumatol Dis 2001;60:218-22, doi:10.1136/ard.60.3.218.

12. Lu C, Chang W, Lui C. Adult spinal epidural abscess: clinical features and prognostic factors. Clin Neurol Neurosurg 2002; 104:306-10, doi:10.1016/S0303-8467(02)00020-3.

13. Xiao B, Wang C, Lin J. Successful medical treatment of spinal epidural abscess. $\mathcal{F}$ Microbiol Immunol 2008;41:180-2.

14. Davis DP, Wold RM, Patel RJ, et al. The clinical presentation and impact of diagnostic delays on emergency department patients with spinal epidural abscess. 7 Emerg Med 2004;26:285-91, doi:10.1016/j.jemermed.2003.11.013.

15. Davis DP, Salazar A, Chan TC, Vilke GM. Prospective evaluation of a clinical decision guideline to diagnose spinal epidural abscess in patients who present to the emergency department with spine pain. 7 Neurosurg Spine 2011;14:76570. [Epub 2011 Mar 18], doi:10.3171/2011.1.SPINE1091.

16. Panagiotopoulos V, Konstantinou D, Solomou E. Extended cervicolumbar spinal epidural abscess associated with paraparesis successfully decompressed using a minimally invasive technique. Spine 2004;29:E300-3, doi:10.1097/01.BRS. 0000131215.46119.DD.

17. Riaz S, Mahmood JK. Extensive spinal epidural abscess. 7 Ayub Med Coll Abbottabad 2007;19(2):64-7.

18. Schultz KD Jr, Comey CH, Haid RW Jr. Technical note. Pyogenic spinal epidural abscess: a minimally invasive technique for multisegmental decompression 7 Spinal Disord Tech 2001;14:546-9, doi:10.1097/00002517-200112000-00015. 